\title{
Iso Efficiency Contour Measurement Results for Variable Speed Drives
}

\author{
Kurt Stockman, Steve Dereyne, Dirk Vanhooydonck, Wim Symens, Joris Lemmens, Wim Deprez
}

\begin{abstract}
The efficiency of variable speed drives with induction motors and permanent magnet synchronous motors has received little attention so far in international standards. However the number of such applications is increasing rapidly and the potential energy savings are large. This paper is based on a measurement campaign of three collaborating research institutes and reports on the efficiency of motors up to $15 \mathrm{~kW}$. The efficiency values are represented by means of iso efficiency contours. From these contours, the efficiency for IE1, IE2 and IE3 induction motors is compared with that of a permanent magnet machine for the entire torque - speed operation region. Also the impact of flux optimization with induction motors is analyzed. The required number of measurement points to construct accurate iso efficiency contours with minimum measurement effort is also discussed.
\end{abstract}

Index Terms - AC motor drives, induction motors, permanent magnet machines, measurement standards

\section{INTRODUCTION}

$\mathrm{E}$ lectric motor systems in industry are responsible for approximately $60 \%$ of the total electric consumption [1]-[3]. The majority of the industrial motors are induction machines and a growing number of these motors are speed controlled. This enables accurate speed and torque control or energy savings in applications with centrifugal pumps or fans. In applications with high dynamic requirements the induction motors are challenged by other motor types such as permanent magnet synchronous machines. These motors can only be operated by means of a power electronic converter or variable speed drive (VSD). They often have higher efficiency compared to the induction motors. The potential energy savings when using high efficiency electric motors and proper use of VSDs was estimated at 181 TWhe in Europe in 2000 [3]. To stimulate the introduction of drive systems with increased efficiency, the IEC 60034-30 standard was approved in 2008 [5]. This standard defines efficiency classes IE1, IE2 and IE3 for direct on line (DOL) induction motors up to $375 \mathrm{~kW}$. Internationally approved standards or testing protocols for motors with VSDs are not available at present. Some initiatives however have been set

This work was supported in part by the Flemish Government (IWT), grant IWT80144.

K. Stockman and S. Dereyne are with Technical University College of West-Flanders, Graaf Karel de Goedelaan 5, Kortrijk 8500, Belgium and Department of Electrical Energy, Systems and Automation, Ghent University, Gent 9000, Belgium (e-mail: kurt.stockman@howest.be and steve.dereyne@howest.be).

D. Vanhooydonck and W. Symens are with Flanders' Mechatronics Technology Centre (FMTC), Celestijnenlaan 300D, 3001 Leuven, Belgium (e-mail: dirk.vanhooydonck@fmtc.be and wim.symens@fmtc.be).

W. Deprez and J. Lemmens are with Katholieke Universiteit Leuven, Dept. Electrical Engineering (ESAT), Div. ELECTA, Kasteelpark Arenberg 10, 3001 Heverlee, Belgium (e-mail: wim.deprez@esat.kuleuven.be, joris.lemmens@esat.kuleuven.be). up to support the standardization process for VSDs [6]. Therefore this paper reports on the initiative of three collaborating research institutes to give guidance to future standardization initiatives for VSD systems [12][13].

A VSD can operate the motor in a wide operating range. Unlike with DOL motors, efficiency values are required for each operating point of the system. To represent the efficiency, the concept of iso efficiency contours or efficiency maps is used (Fig. 1). Iso efficiency contours are frequently used in combustion motor technology and drive train design of electric vehicles [8][7][9]. The generation of these contours in bases on a set of efficiency measurement points spread over the operating region of the motor drive combination. The determination of the required number of measurement points to generate accurate contours is essential to limit the measurement effort. In [6] it was discussed that the number of measurement points could be limited to two zones as only VSD applications with constant torque or square torque were considered. However, in many applications the VSD operates the motor in the entire torque speed range. Typical applications are handling machines, industrial washing machines, winding machines, ... After some theoretical considerations on the energy losses of IM and PMSM in section II, section III discusses the minimum number of measurement points required to identify the efficiency in the entire operating region. This procedure is applied to a measurement campaign on induction motor and permanent magnet synchronous machines in the power range from $0.75 \mathrm{~kW}$ up to $15 \mathrm{~kW}$. Section IV compares the efficiency for DOL versus VSD operation for IE1, IE2 and IE3 induction motors. In Section V, VSD operation of induction motors with flux optimization is compared with permanent magnet machines.

\section{ANALYTICAL ASSESSMENT OF ISO EFFICIENCY CONTOURS FOR INDUCTION MOTORS}

Induction motors (IM) with squirrel-cage rotor are widely used in industry. The required efficiency for these machines operated direct on line (DOL) is described in the IEC 6003430 standard making a distinction between IE1, IE2 and IE3 efficiency classes [5]. The ohmic losses in both stator and rotor are the dominant losses in induction machines. Other losses are the iron losses, ventilation losses and stray load losses. The distinction between the efficiency classes is obtained by using better conductor material, better iron and an optimized design of both stator and rotor. When supplied by a variable speed drive (VSD) the induction motors are prone to additional losses due to the distortion in the voltage and current waveforms imposed on the machine. The additional losses will be illustrated in section IV.

To get an idea of the efficiency of a speed controlled induction motor in its entire operating range, the different 
loss components were calculated starting from the equivalent scheme of the machine. By doing so, the stray load losses and the additional losses due to the inverter operation are not taken into consideration here. Fig. 1 illustrates the results for a $4 \mathrm{~kW}$, IE1, 400V, $1500 \mathrm{rpm}$ IM. The optimal efficiency is located in the field weakening region. Lower magnetization current during field weakening results in reduced ohmic losses [8]. At very high speeds the efficiency is reducing because of the increase of the ventilation and friction losses. In the range of rated speed, the ohmic losses in the rotor and the ohmic losses related to the magnetization current decrease the efficiency compared to the optimal value in the field weakening range. When the machine is operated at reduced speed and torque the iso efficiency lines become more concentrated. The efficiency falls rapidly due to the high rotor losses. From a measurement point of view this will require more measurement points in these regions.

For the power range considered in this paper, permanent magnet synchronous machines (PMSM) are often used in applications with high dynamic requirements. The magnetic excitation in this machine is provided by permanent magnets in the rotor. Compared to the induction machine, no magnetization currents are required in the stator and no current is needed in the rotor. The dominant losses are the iron losses which mainly occur in the stator. In the rated speed range the PMSM efficiency is therefore expected to have higher efficiency compared to the IM. In the field weakening range additional stator current is required to counteract the permanent magnets. As a result the efficiency decreases at high speeds. The major disadvantage compared to the IM is the high cost of the magnets.

\section{MEASUREMENT CAMPAIGN OUTLINE}

\section{A. Measurement setup}

The scope of the measurement campaign is to determine the efficiency of speed controlled induction motors and permanent magnet synchronous motors in a power range from $0.75 \mathrm{~kW}$ up to $15 \mathrm{~kW}$ and speed range from zero up to $3000 \mathrm{rpm}$. This paper reports on the results for motors with a rated speed of $1500 \mathrm{rpm}$. Each VSD and motor combination is tested up to $200 \%$ of the rated speed and, if possible, up to $150 \%$ of rated torque.

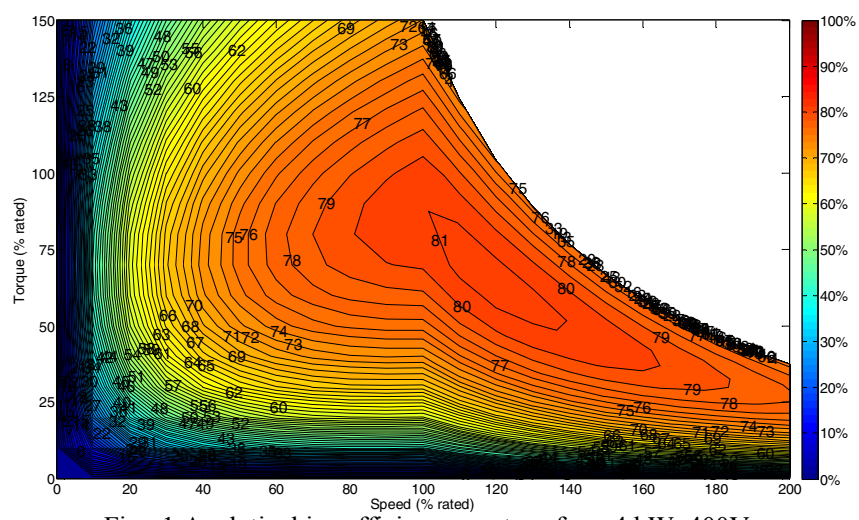

Fig. 1 Analytical iso efficiency contour for a $4 \mathrm{~kW}, 400 \mathrm{~V}$, $1500 \mathrm{rpm}$ induction motor
The aim is to conduct steady state measurements, ie. constant speed and constant load torque. The loading of the motor is realized by means of an induction machine with VSD in field oriented torque control mode and speed feedback (Fig. 2). The design of the measurement setup guarantees reproducible measurement results and high accuracy. The direct method is used to determine the overall efficiency of the motor and drive combinations. Indirect efficiency measurement methods as specified in IEEE and IEC efficiency standards [10],[11] cannot be used here. The direct method requires accurate measurement of the mechanical output power and the electric input power. The output power is measured by means of a torque and speed sensor. Due to the wide spread in power range two mechanical setups were realized. The first one is used for motors up to $4 \mathrm{~kW}$, the second one for motors up to $15 \mathrm{~kW}$. Each setup is equipped with a dedicated torque sensor with an accuracy of $0.2 \%$. The electric power and the output of the torque and speed sensors are measured with a Yokogawa WT 1600 power analyzer. This allows for perfect synchronization of the input and output power measurements and reliable efficiency calculation. The electric connections of the power analyzer also allows the measurement of the electric power at the output of the variable speed drive. As a result, the VSD efficiency and the motor efficiency can be determined separately.

In order to guarantee reproducibility, a measurement protocol is setup. Before starting the actual efficiency measurements, the motor is loaded at rated value until it reaches a stable operation temperature. During the measurements at different torques and speeds, a temperature window of $5^{\circ} \mathrm{C}$ is allowed. Finally, also the supply voltage quality is monitored.

\section{B. Accuracy and number of measurement points}

The determination of the minimum number of measurement points required to obtain an accurate iso efficiency contour for a VSD and motor combination is essential. A high number of points results in an expensive, time consuming measurement campaign. If the number of measurements is too low, the accuracy to determine the overall efficiency for a given load profile may be too low.

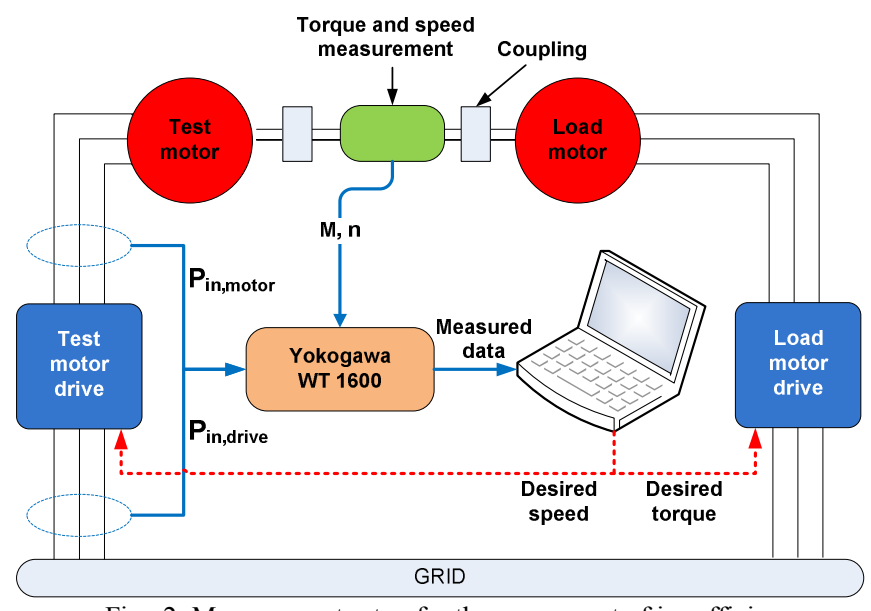

Fig. 2: Measurement setup for the assessment of iso efficiency contours by means of the direct method. 
The analytical iso efficiency contour for an induction motor shows a high concentration of iso efficiency lines near the speed and torque axes. The region of the rated torque and speed of the motor is characterized by a lower gradient. From this observation a higher concentration of measurement points nearby the axes seems obvious.

A first measurement was setup with a high number of measurement points to serve as a reference measurement. The efficiency was determined for 40 torque values and 40 speed values equally spread over the axes resulting in a $40 \times 40$ efficiency matrix. A linear interpolation algorithm is used to draw the iso efficiency lines in the torque-speed plane from the measurement points. The algorithm is implemented in Matlab. Fig. 3 illustrates the process. The measured values form a rectangle. Line C(i) is a line of constant efficiency and is interpolated by using the surrounding measurement points. Efficiency lines with an interval of $1 \%$ are drawn. Next, starting from the $40 \times 40$ efficiency matrix the number of measurement points was decreased gradually to find the optimum number of points required. The tolerated error between the curves from the reference measurement set $(40 \times 40)$ and the reduced measurement set is $\pm 0.5 \%$. From this analysis it was found that 16 torque values and 19 speed values need to be considered reducing the number of measurement points from 1600 down to 304. As can be seen from Fig. 4 the measurement points are not evenly distributed over the entire operating area of the drive system. A higher concentration is required in the regions near zero torque and zero speed. Fig. 4 also illustrates the absolute measurement error in the different regions of the operating range.

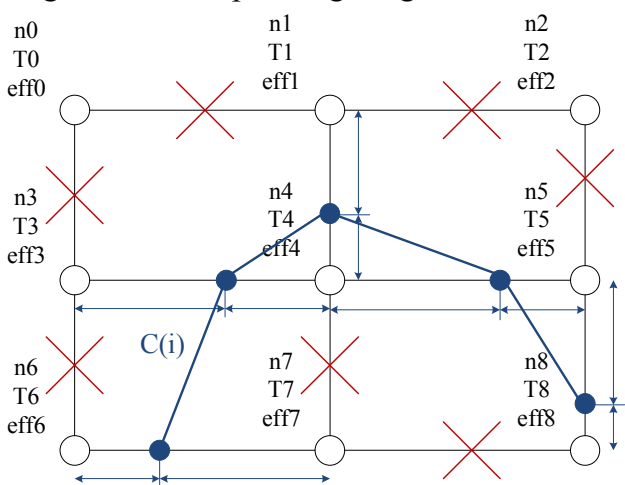

Fig. 3: Graphical interpretation of the interpolation algorithm to find the location of the line of constant efficiency C(i).

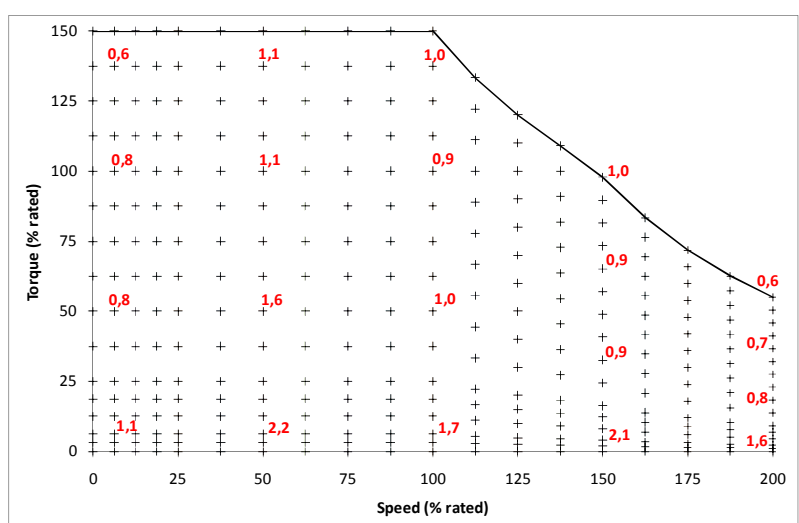

Fig. 4: Distribution of the measurement points and indication of the absolute errors of the measurement setup for a $4 \mathrm{~kW}, 1500 \mathrm{rpm}$ IM and torque sensor $50 \mathrm{Nm}, 0.2 \%$

\section{DIRECT ON LINE VERSUS INVERTER DRIVEN INDUCTION MOTOR}

The efficiency values for induction motors as specified in catalogues and in the IEC 60034-30 are valid for direct on line operation only. When operated by means of a VSD, the overall efficiency of the system is reduced compared to DOL operation. During the measurement campaign each motor is tested in both DOL operation and VSD operation. For VSD operation, both the efficiency of the motor and the efficiency of the drive is measured. When measuring motors with different efficiency classes but identical power rating, the same VSD is used. Only the appropriate motor parameters are changed compared to the factory settings. If available in the VSD, the autotuning procedure is performed. The VSD is operating the motors by means of a U/f-control or field oriented control. To be able to compare the results for DOL and VSD operation, measurements are taken at identical speed and torque values. The switching frequency of the inverter is not altered in this measurement campaign and set at $5 \mathrm{kHz}$. Measurement results for other switching frequencies are still ongoing and will be reported in near future.

Fig. 5 and Fig 6 give the results for an IE1 and IE2 $4 \mathrm{~kW}$, $400 \mathrm{~V}, 1500 \mathrm{rpm}$ IM. The solid line gives the efficiency for DOL operation, the red dot indicates the efficiency at rated speed and torque as specified in IEC 60034-30. The efficiency is at its maximum at about 60 to $70 \%$ of the rated torque for both machines. The maximum efficiency for the IE2 IM is $87 \%$ which is an increase of $3 \%$ compared to the maximum efficiency of the IE1 IM. Starting from the maximum efficiency, for the IE2 machine the efficiency drops much slower with higher loading. The dotted line gives the overall efficiency of the IM with VSD operation. The maximum efficiency is reduced by a $2.5 \%$ for both machines. At rated load, the efficiency is reduced by $3 \%$. The dashed line finally gives the IM efficiency when fed by the VSD. At rated torque the efficiency compared to the DOL operation is reduced by only $1 \%$. It is also observed that at partial load the motor efficiency when fed by the VSD equals the efficiency of the DOL operation. Careful analysis of the voltage and current waveforms shows that the VSD applies lower magnetization values for the IM resulting in a reduction of the losses compared to DOL.

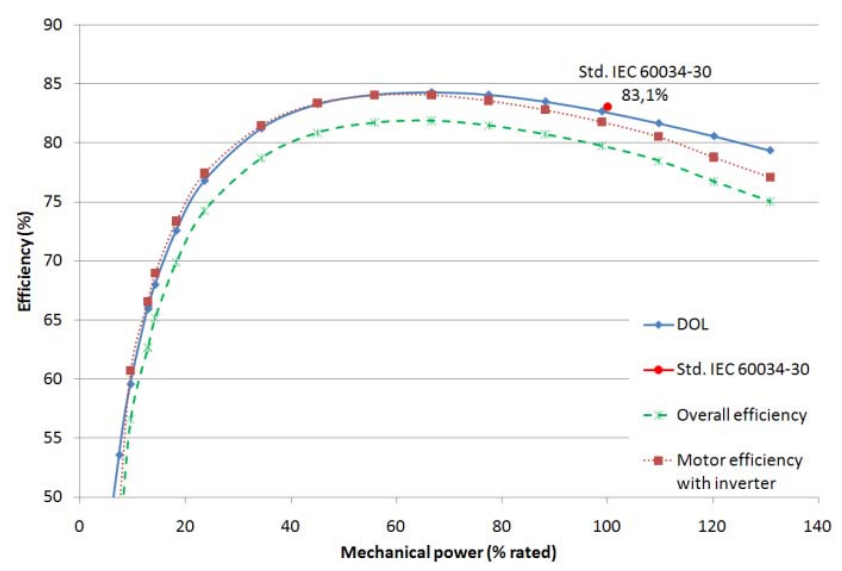

Fig. 5 Efficiency values for an IE1 $4 \mathrm{~kW}, 400 \mathrm{~V}, 1500 \mathrm{rpm}$ induction motor for direct on line operation (DOL) and inverter operation (overall efficiency and motor efficiency). 


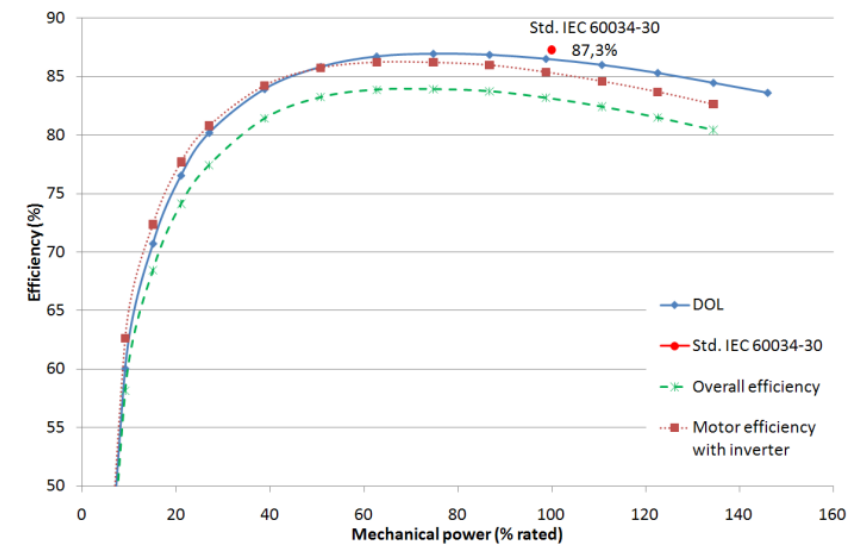

Fig. 6 Efficiency values for an IE2 $4 \mathrm{~kW}, 400 \mathrm{~V}, 1500 \mathrm{rpm}$ induction motor for direct on line operation (DOL) and inverter operation (overall efficiency and motor efficiency).

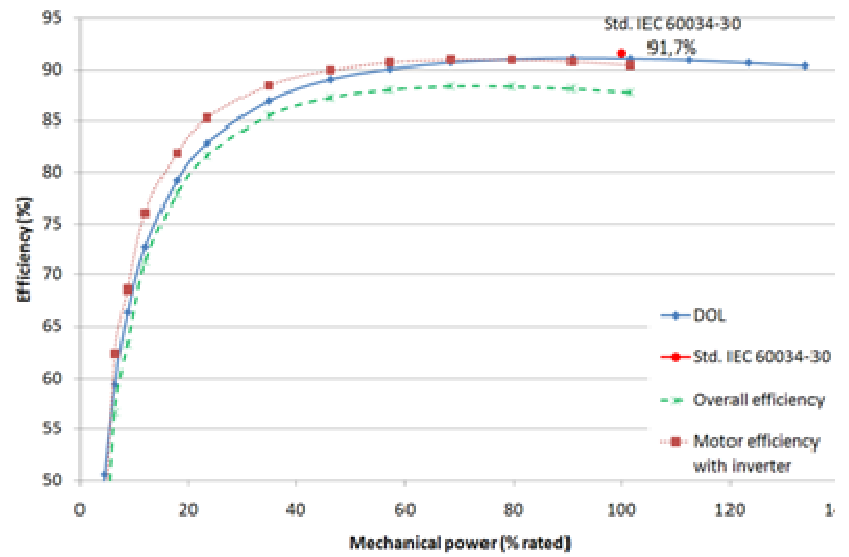

Fig. 7 Efficiency values for an IE3 $11 \mathrm{~kW}, 1500 \mathrm{rpm}$ induction motor for direct on line operation (DOL) and inverter operation (overall efficiency and motor efficiency).

Fig. 7 shows the efficiency for an IE3, $11 \mathrm{~kW}, 400 \mathrm{~V}, 1500$ rpm IM. For low torques, the motor efficiency when operated by a VSD is $2 \%$ higher compared to DOL operation. This effect is however counteracted by the efficiency of the VSD itself resulting in an overall efficiency lower than it is the case for DOL. For the IE3, $11 \mathrm{~kW}$ machine is also observed that the maximum efficiency of $91.5 \%$ is reached at $100 \%$ torque and remains close to this value over a wide torque range.

\section{ISO EFFICIENCY CONTOURS}

\section{A. $11 \mathrm{~kW}$ induction motor}

This section analyzes the iso efficiency contours for three $11 \mathrm{~kW}, 400 \mathrm{~V}, 1500 \mathrm{rpm}$ IM with efficiency classes IE1, IE2 and IE3. The contours are given in Fig. 8, Fig. 9, Fig. 10 respectively. They represent the overall efficiency of the VSD and motor combination. As it was expected from the analytical approximation of the contour in section II, the maximum efficiency is reached mainly in the field weakening range. Values for maximum efficiency are $86 \%$, $87 \%$ and $88 \%$ for respectively IE1, IE2 and IE3 classes. In Fig. 11, the iso efficiency contours for the IE3 and IE1 11 $\mathrm{kW}$ IM are subtracted to find the efficiency improvement contour map. It is observed that a $2 \%$ efficiency improvement is available in a wide operating area. For high torque values at both low and high speed, even a larger improvement is noticed. The same observations can be made when comparing the $11 \mathrm{~kW}$ IE2 and IE1 contour maps (Fig. 12).

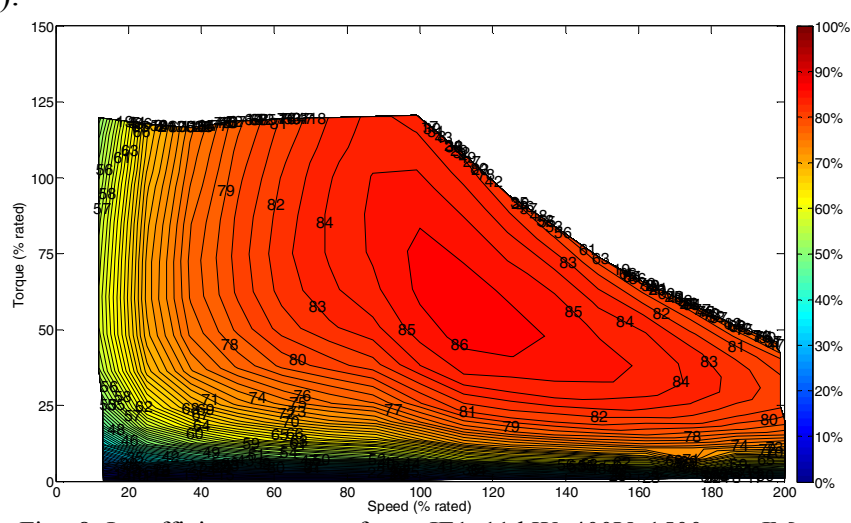

Fig. 8: Iso efficiency contour for an IE1, $11 \mathrm{~kW}, 400 \mathrm{~V}, 1500 \mathrm{rpm}$ IM.

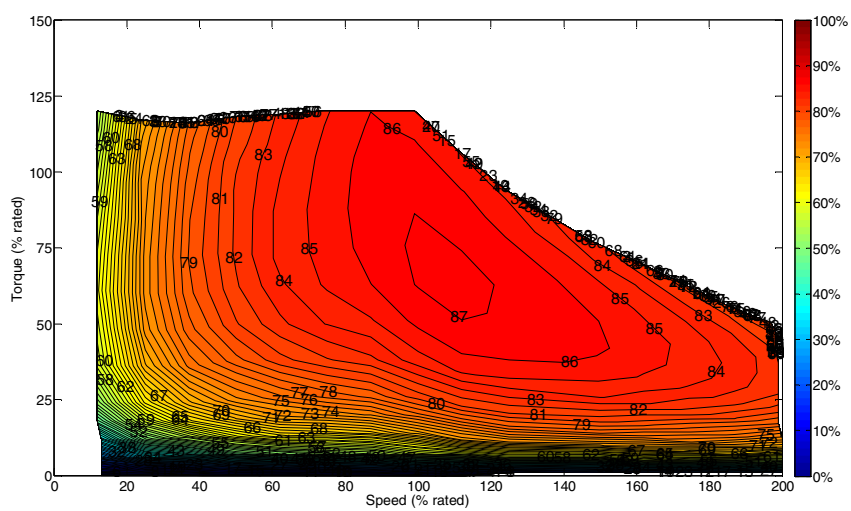

Fig. 9: Iso efficiency contour for an IE2, $11 \mathrm{~kW}, 400 \mathrm{~V}, 1500 \mathrm{rpm}$ IM.

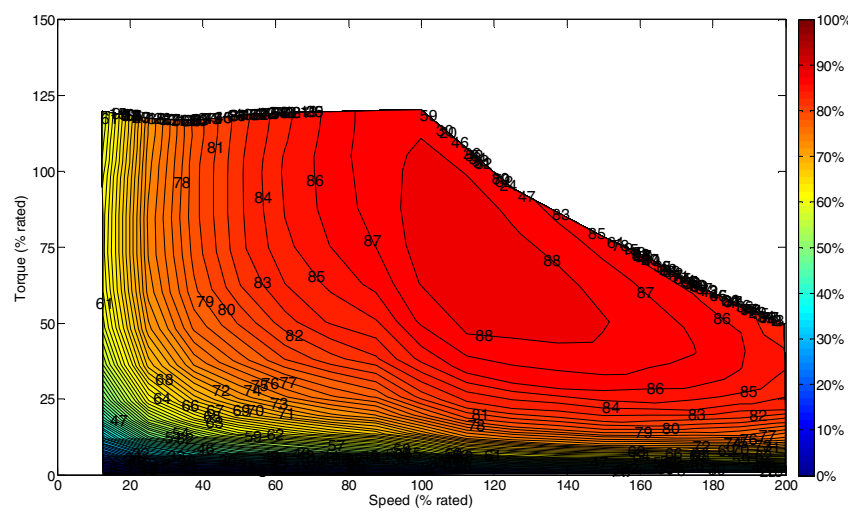

Fig. 10: Iso efficiency contour for an IE3, $11 \mathrm{~kW}, 400 \mathrm{~V}, 1500 \mathrm{rpm}$ IM.

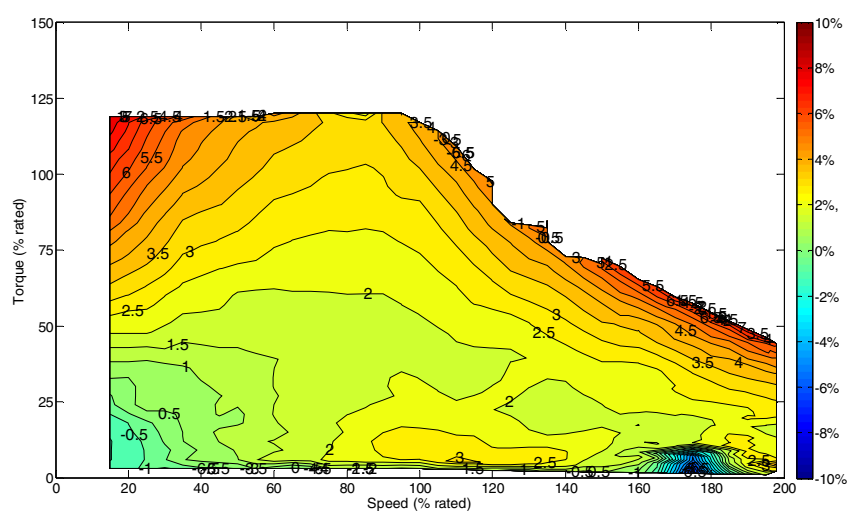

Fig. 11: Efficiency improvement contour map for an IE3 versus IE1 IM, $11 \mathrm{~kW}, 400 \mathrm{~V}, 1500 \mathrm{rpm}$. 


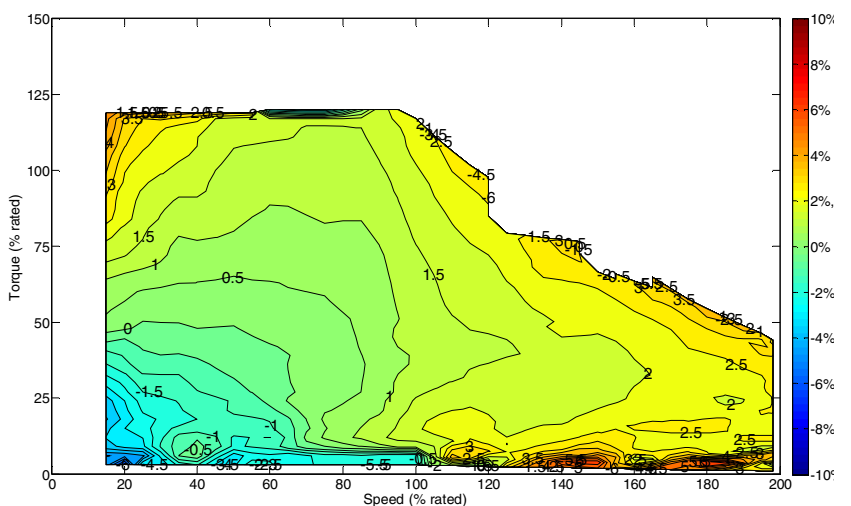

Fig. 12: Efficiency improvement contour map for an IE3 versus IE1 IM, $11 \mathrm{~kW}, 400 \mathrm{~V}, 1500 \mathrm{rpm}$.

\section{B. Induction motor versus Permanent magnet motor}

In this section measurement results for a $4 \mathrm{~kW}$ IM and a PMSM in the same power range are discussed. The Iso efficiency contours were measured for each motor. Fig. 13 shows the efficiency improvement contour map for the PMSM motor versus an IE2 IM. As expected from section II, the efficiency of the PMSM is better compared to the IM. An improvement of at least $4.5 \%$ is observed. An even higher improvement is observed for operating points with low speed and low torque and operating points with high speed and high torque value as can be seen in Fig. 13. The PMSM is tested up to $3000 \mathrm{rpm}$ and is not used in the field weakening range. The increased efficiency is mainly the result of the lack of magnetization current in the PMSM.

When an IM is operated at lower torque than rated, the magnetization level can be reduced. This is commonly available in commercial drives and is known as flux optimization.The flux level is lowered resulting in a reduction of the stator current resulting in lower ohmic losses and lower magnetic losses thus increasing the efficiency. The measurement results for an IM with a commercial flux optimization algorithm can be found in Table I. For different operating points the efficiency improvement referred to the efficiency of an IE1 induction motor, which act as a reference here, for an IE2, IE2 with flux optimization and a PMSM are given. All values are related to $4 \mathrm{~kW}, 1500 \mathrm{rpm}$ induction machines and a 3000 rpm, 18 Nm PMSM.

A noticeable efficiency improvement of the PMSM over the IE1 and IE2 IM is clearly illustrated for every operating point. When the results for the PMSM are compared with the IE2 IM with flux optimization, similar efficiency values are measured. It can be concluded that for steady state operation the use of a PMSM over an IM with flux optimization can not be motivated. The disadvantage of flux optimization is the relatively slow dynamics of the flux levels. For applications requiring high torque dynamics, flux optimization can become impossible. If however the torque requirements can be foreseen, programming of the flux level in the IM can be regarded as a promising technique to further optimize the efficiency of an IM .

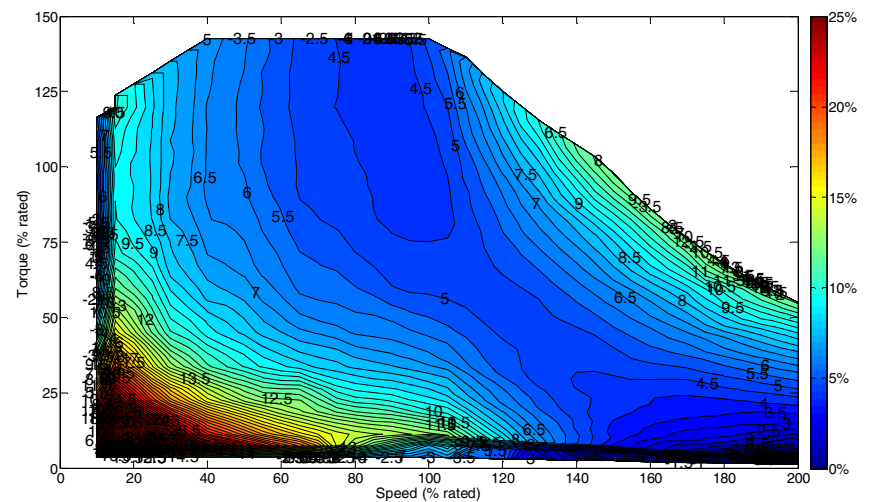

Fig. 13: Efficiency improvement contour map for PMSM (3000rpm, 18Nm) versus IE2 IM (4 kW, 400V, $1500 \mathrm{rpm})$.

TABLE I

EFFICIENCY VALUES FOR A $4 \mathrm{KW}, 1500$ RPM, IE1 INDUCTION MOTOR AND EFFICIENCY IMPROVEMENT $\Delta \eta$ COMPARED TO IE1 FOR IE2, IE2 WITH FLUX OPTIMIZATION (FLUX) AND A PERMANENT MAGNET MACHINE (3000 RPM, 18 NM) FOR DIFFERENT OPERATING POINTS T-N.

\begin{tabular}{|c|c|c|c|c|c|}
\hline $\begin{array}{c}\mathbf{T}_{\text {rated }} \\
{[\%]}\end{array}$ & $\begin{array}{c}\mathbf{n}_{\text {rated }} \\
{[\%]}\end{array}$ & $\begin{array}{c}\eta \text { IE } 1 \\
{[\%]}\end{array}$ & $\begin{array}{c}\Delta \eta \text { IE2 } \\
{[\%]}\end{array}$ & $\begin{array}{c}\Delta \eta \text { IE2 } \\
\text { Flux }[\%]\end{array}$ & $\begin{array}{c}\Delta \eta \text { PM } \\
{[\%]}\end{array}$ \\
\hline $\mathbf{5}$ & $\mathbf{1 4}$ & 18 & 3 & 25 & 28 \\
\hline $\mathbf{5}$ & $\mathbf{5 0}$ & 33 & 7 & 17 & 19 \\
\hline $\mathbf{5}$ & $\mathbf{1 0 0}$ & 35 & 5 & 18 & 12 \\
\hline $\mathbf{5 2}$ & $\mathbf{1 4}$ & 53 & 4 & 6 & 18 \\
\hline $\mathbf{5 2}$ & $\mathbf{5 0}$ & 77 & 3 & 3 & 10 \\
\hline $\mathbf{5 2}$ & $\mathbf{1 0 0}$ & 84 & 2 & 2 & 7 \\
\hline $\mathbf{1 0 5}$ & $\mathbf{1 4}$ & 41 & 8 & 11 & 18 \\
\hline $\mathbf{1 0 5}$ & $\mathbf{5 0}$ & 72 & 5 & 6 & 11 \\
\hline $\mathbf{1 0 5}$ & $\mathbf{1 0 0}$ & 81 & 4 & 3 & 8 \\
\hline
\end{tabular}

\section{CONCLUSION}

This paper presents results of a measurement campaign to identify the efficiency of variable speed drives for induction motors (IM) and permanent magnet synchronous machines (PMSM). Iso efficiency contours are presented as a necessary tool to visualize the efficiency of the drive system in its entire operating region. The number of measurement points required to obtain a reliable iso efficiency contour with an accuracy of $1 \%$ is discussed. Contours for induction motors of efficiency classes IE1, IE2 and IE3 in a power range from $0.75 \mathrm{~kW}$ up to $15 \mathrm{~kW}$ are presented. Optimum efficiency is only reached in the field weakening region. The IM efficiency is finally compared to the efficiency of a PMSM. The PMSM has far better efficiency values due to the permanent magnet excitation. If however the VSD for the IM applies a flux optimization algorithm, similar efficiencies as with PMSM can be reached.

\section{ACKNOWLEDGMENT}

The research described in this paper has been the result of a fruitful collaboration between three research institutes: FMTC, ELECTA (ESAT) and Howest. 


\section{REFERENCES}

[1] A.T. de Almeida, F.J.T.E. Ferreira and D. Both, "Technical and economical considerations in the application of variable-speed drives with electric motor systems," IEEE Transactions on Industry Applications, 41(3), pp. 188-199, Jan.-Febr 2005.

[2] R. Belmans, F. Vergels, M. Machiels, J. Driesen, B. Collard, L. Honóri, M.H. Laurent, H. Zeinhofer and M.A. Evans, "Electricity for more efficiency: Electric technologies and their energy savings potential," Eurelectric \& UIE, Ref:2004-440-0002, July 2004

[3] H. De Keulenaer, R. Belmans, P. Radgen and A.T. de Almeida, "Energy Efficient Motor Driven Systems... can save Europe 200 billion $\mathrm{kWh}$ of electricity consumption and over 100 million tons of greenhouse gas emissions a year," Brussels, Belgium: European Copper Institute, 2004.

[4] A.T. de Almeida, "Improving the penetration of energy-efficient motors and drives," DG TREN 2000, European Commission, p. 114, 2000 .

[5] Rotating electrical machines - Part 30: Efficiency classes of singlespeed, three-phase, cage-induction motors (IE-code). IEC Standard 60034-30, (2008 - 10), 2008.

[6] A.T. de Almeida, P. Angers, C.U. Brunner and M Doppelbauer,"Motors with adjustable Speed Drives: Testing, Protocol and Efficiency Standard," EEMODS '09 Energy Efficiency in Motor Driven Systems, Nantes, France, 2009.

[7] S.S. Williamson, S.M. Lukic and A. Emadi, "Comprehensive Drive Train Efficiency Analysis of Hybrid Electric and Fuel Cell Vehicles Based on Motor-Controller Efficiency Modeling," IEEE Transactions on Power Electronics, 21(3), pp. 730-740, May 2006

[8] T. Finken and K. Hameyer, "Design of Electric Motors for Hybridand Electric- Vehicle Applications," $12^{\text {th }}$ International Conference on Electrical Machines and Systems, ICEMS 2009, Tokyo, Japan, 2009.

[9] R.H. Staunton, C.W. Ayers, L.D. Marlino, J.N. Chiasson and T.A. Burress, "Evaluation of 2004 Toyota Prius Hybrid Electric Drive System." Oak Ridge National Laboratory, Technical Report ORNL/TM-2006/423, May 2006.

[10] IEEE Standard Test Procedure for Polyphase Induction Motors and Generators, IEEE Std 112-2004 (Revision of IEEE Std 112-1996) 2004 .

[11] Rotating electrical machines - Part 2, Ed. 4: Methods for determining losses and efficiency from tests (excluding machines for traction vehicles). IEC Standard 60034-2 Ed. 4, 2007.

\section{Papers Presented at Conferences (Unpublished):}

[12] D. Vanhooydonck, W. Symens, W. Deprez, J. Lemmens, K. Stockman, S Dereyne, "Calculating Energy Consumption of Motor Systems with Varying Load using Iso Efficiency Contours," submitted for ICEM '10: International Conference on Electrical Machines, Rome, Italy, 2010.

[13] W. Deprez, J. Lemmens, D. Vanhooydonck, W. Symens, K. Stockman, S. Dereyne, J. Driesen, "Iso Efficiency Contours as a Concept to Characterize Variable Speed Drive Efficiency," submitted for /ICEM '10: International Conference on Electrical Machines, Rome, Italy, 2010.

\section{BIOGRAPHIES}

Kurt Stockman was born in Belgium in 1972. He received the Master degree in electrotechnics from Provinciale Hogeschool West-Vlaanderen, Kortrijk, Belgium in 1994 and the Ph.D. degree an Katholieke Universiteit Leuven, in 2003. He is currently professor at University College Howest, Kortrijk, Belgium. His research interests include control of electrical machines, energy efficiency and reliability of adjustable speed drives.

Steve Dereyne was born in Belgium in 1979. He received his Master degree in electrotechnics from Provinciale Hogeschool West-Vlaanderen, Kortrijk, Belgium in 2001. He is currently assistant at University College Howest, Kortrijk, Belgium. His research interests include motortesting, energy efficiency and design of electrical LV-grids.

Dirk Vanhooydonck received the M.Sc. degree in mechanical engineering, option mechatronics (1999) and the Ph.D. in applied sciences, focusing on robotics (2007), both from the Katholieke Universiteit Leuven. Currently he is involved at the Flanders' Mechatronics Technology Centre (FMTC) in projects dealing with energy efficiency of high-productivity machines.

Wim Symens graduated in 1999 from the Katholieke Universiteit Leuven as a mechanical engineer, option mechatronics and obtained the $\mathrm{PhD}$ degree in mechanical engineering for the same university in 2004. His $\mathrm{PhD}$ research was dealing with "Motion and vibration control of mechatronic systems with variable configuration and local non-linear friction". After that, he started at FMTC, which was at that moment in operation only for half a year, as responsible for FMTC's "High-productivity Machines" research program.

Wim Deprez received the M.Eng. degree in electromechanical engineering and material sciences from the Group T, University College Leuven, Belgium. In 2002 and 2008 respectively, he received the M.Sc. Eng. degree in electromechanical engineering and the $\mathrm{Ph} . \mathrm{D}$. degree in electrical engineering from the K.U. Leuven. Currently, he is assigned as postdoctoral researcher at the research group ELECTA, Department of Electrical Engineering (ESAT), K.U. Leuven. His research interests include energy efficient motor technologies, motor design, motor testing, and standards.

Joris Lemmens received the M.Eng. degree in electromechanical engineering in 2008 from the KHLim University College, Diepenbeek, Belgium. Currently, he is working towards a Ph.D. degree at the research group ELECTA, K.U. Leuven. His areas of interest include FEM motor design, energy efficiency in MDS, motor control and power electronics. 